\title{
Seismic impacts influence on the slope stability on the example of Abrau Peninsula (Russian sector of black sea coast)
}

\author{
Mihail Kropotkin ${ }^{1, *}$ \\ ${ }^{1}$ Moscow State University of Civil Engineering, 26, Yaroslavskoe shosse, Moscow, Russia
}

\begin{abstract}
Some aspects of seismic impact on the stability of massive seismogravitational solid masses are examined. An example of the slope stability calculation using separate accounting for seismic accelerations in blocks is shown. The influence of the relief on the change in seismic effects is considered. Some aspects of seismic impact on the stability of massive seismogravitational solid masses are examined. An example of the slope stability calculation using separate accounting for seismic accelerations in blocks is shown. The influence of the relief on the change in seismic effects is considered. The comparative impact of longitudinal and transverse seismic waves from the earthquake focuses located in front of the slope foot and behind the slope ridge is evaluated.
\end{abstract}

\section{Introduction}

The risk assessment of large gravitational displacements induced by earthquakes attracts widespread attention of specialists. However, in many cases, slope stability estimations are performed for isolated objects without taking into account the seismological situation (direction and angles of approach of seismic waves, difference in the effects of seismic vibrations of different types, intensity changes depending on soil properties, etc.) and with insufficient consideration of the effect of the relief plot. In addition, slope stability estimations are usually performed with the same parameters of seismic impact for the entire potential landslide body. This article provides an example of a partial accounting of the above-named parameters for the landslide area of the Western Caucasus coast.

A unique feature of the Caucasian shores is the presence of large number of paleoseismic dislocations, represented by large block landslides and rockfalls [1, 2].

The activation of the displacements of these massifs, as well as their newly formed structures during possible earthquakes, poses a great threat to the actively developed coastal zone, where resort facilities, roads, terminals of large pipelines, objects of air and sea space control, etc. are located.

The Abrau Peninsula is one of the sites with the active development of very large and giant displaced block massifs.

As the typical site a massif, on which a rocky landslide of shear was identified, with a length (in dip) of $160 \mathrm{~m}$ and a width of about $700 \mathrm{~m}$ was selected. Its thickness varies from

*Corresponding author: singeos@narod.ru 
$20 \mathrm{~m}$ to $60 \mathrm{~m}$, decreasing down the slope. The landslide tongue is cut off by an active cliff whose height reaches $30 \mathrm{~m}$ (Fig. 1). The geological section is represented by gray strongly weathered gray marlstone, highly fractured, of low strength, with interlayers of fractured limestone.

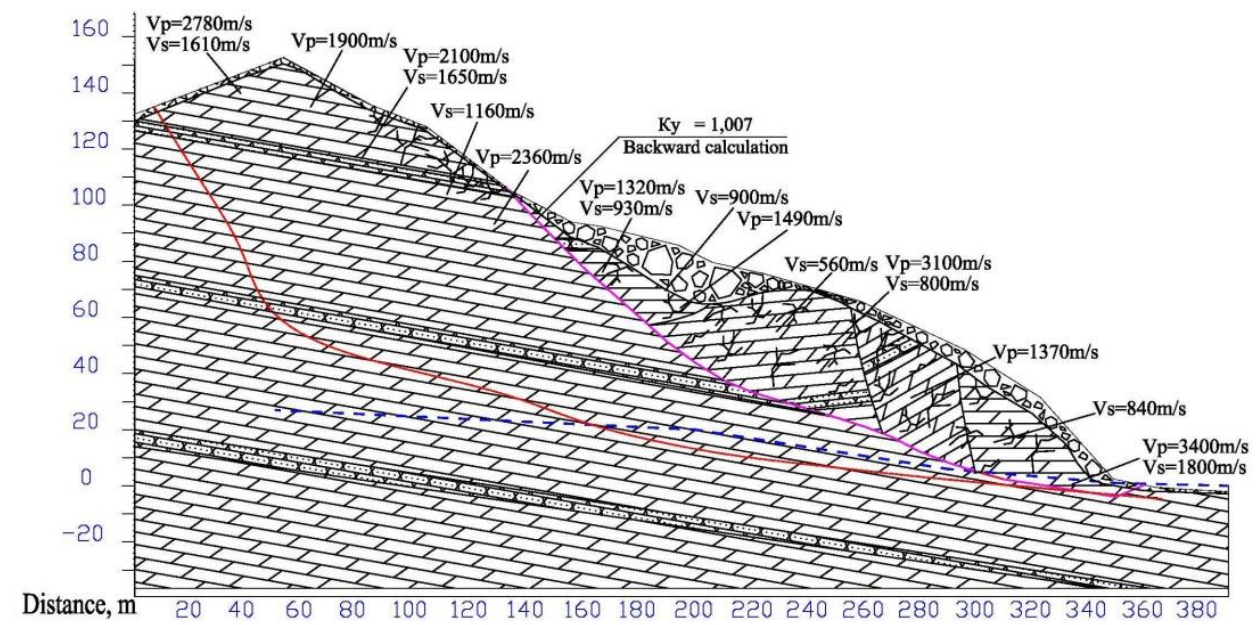

Fig. 1. Schematic geological section of a typical array. Vp is the velocity of longitudinal waves, Vs is the velocity of transverse waves; Fs is the results of the reverse calculation.

The massif, and especially its part displaced in the course of previous landslides, is characterized by intense fracturing and partial bending, which makes it possible to use software complexes used for the stability estimation of massifs composed of dispersed and dispersed coarse-grained soils [3]. The programs PSK-98M5A and PSK-2018, which perform an automated search of the real or potential displacement surface of any shape with a minimum stability coefficient in a two-dimensional formulation, were used.

The programs are based on a mathematical model in the form of a system of limit equilibrium equations, reflecting the ratio of the shear and holding forces in the soil mass, taking into account the forces of interaction along edges of the calculated compartments and the directions of their application. The stability coefficient at each step of the search is calculated with the use of the iterative method by solving the system of equations of equilibrium of horizontal and vertical forces for blocks of a flat slope model. It is possible to take into account the pressure of pressurized groundwater, the pressure of the filtration flow, the effects of various loads, the influence of fracturing systems, etc.

The values of the factor of safety (Fs) over the displacement surface, which is set intuitively by specialists, as a rule, turn out to be $10-20 \%$ higher than the Fs values determined using PSK programs. The results of stability estimations were repeatedly compared with the results obtained by traditional methods (when the position of the most dangerous potential displacement surface was previously found using PSK programs), as well as with estimations based on numerical methods for determining the stress-strain state (SSS) using the wellknown programs such as "PLAXIS", "Phase 2", "FLAC-Slope". All calculations showed high convergence; the differences in the Fs value do not exceed the first percent.

An assessment of the possible strength characteristics of the soils in the massif was based on foreign strength criteria. The parameters of the widespread Hoek-Brown technique were used. With $\mathrm{m}_{\mathrm{i}}=10$ typical for these soils and GSI indices $=25$ units for soil-disturbed soils and 35 units for undisturbed, according to Hoek's nomograms [4], the values were 
determined: $\varphi=24.5^{\circ}$ and $27.5^{\circ}$ and $\mathrm{C}=25 / 21$ (above / below the groundwater level) $\mathrm{KPa}$ and $32 / 28 \mathrm{KPa}$, respectively.

To check the specified characteristics of the soils, reverse calculations were performed for the existing and reliably fixed visually Holocene landslide body. The slope relief was reconstructed for the condition before the creep and the premise that the destruction of the slope mass occurred under the influence of a strong earthquake (9.5 points in the geological and morphological conditions of this section) was accepted. This effect could cause a creep with the following average strength characteristics of soils in the massif: $\varphi=28-29^{\circ}, \mathrm{C}-$ about $50 \mathrm{KPa}$, but with less seismic impact, the critical strength characteristics of soils naturally turn out to be lower.

\section{Analysis of the influence of seismic impacts}

Numerous domestic and foreign studies have shown a significant increase in seismic impact in areas adjacent to edges, ledges, tops of hills and on convex landforms [5].

Theoretical and numerical models predict amplification of oscillations at the peaks, i.e. in "convex" areas, and decrease in the intensity of vibrations in "concave" areas, such as valleys and foothills, and the effect size depends on the characteristics of the incident seismic waves: their types, angles and incidence azimuths (Fig. 2.3). On the hillsides a complex distribution of the areas of amplification and attenuation of seismic signals is predicted.
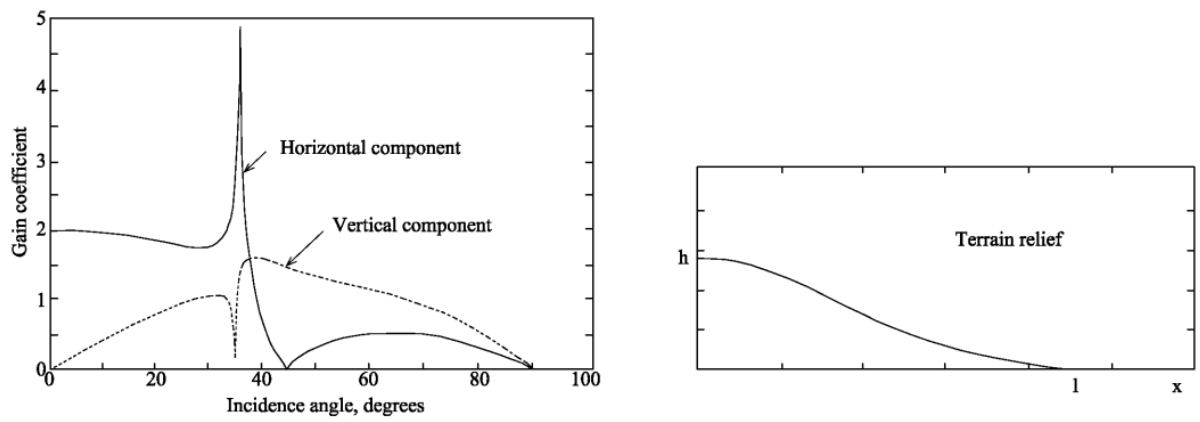

Fig. 2. The dependence of oscillations gain of the wave incidence angle for obliquely incident waves SV for the topographical relief shown on the right (Poisson's ratio is assumed to be 0.25) [6].

Data from records of strong earthquakes also indicate that the topography of the surface significantly affects the amplitude and frequency composition of seismic vibrations. After earthquakes that cause destruction in mountainous areas, it was often reported that buildings on hilltops suffered much more damage than structures located in lowlands. Examples of such reports can be found: for the 1909 Lambesca earthquake, France; for the 1976 Friuli earthquake, Italy; for the 1980 Irpinia earthquake; for the 1985 Chilean earthquake, and others. The recent earthquake of 1995 in Kozani (Northern Greece) provided new evidence of severe destruction in settlements located on hilltops. Observations of unusual surface faults (fallen trees) and dislodged large boulders that indicated vertical accelerations $>1 \mathrm{~g}$ can be explained by topography effects and critical exit angles of SV waves [7, 8].

Topographical effects of earthquakes are caused by 3 main physical mechanisms:

- by the dependence of the intensity fluctuations on the surface (and subsurface layers - M. $\mathrm{K}$.) from the angle of waves incidence (especially visible for vertically polarized shear waves at angles of incidence close to the critical one), reflected in the significant variations of 
vibration intensity when changing the tilt of the surface (Fig. 2). It is indicated that this effect may explain the complex pattern of destruction in the 1987 earthquake in California [6];

- by focusing and defocusing seismic waves reflected from a surface with complex topography [9]. Theoretical studies of this effect for a medium bounded by two intersecting planes (taking into account the absence of phase shift between the incident and reflected waves) have shown that the amplitude of oscillations at the top when the waves are repeatedly reflected is several times greater than the amplitude of the incident wave (Fig. 3);

- by diffraction of body and surface waves reflected from elements of the relief and their interference with the incident waves.
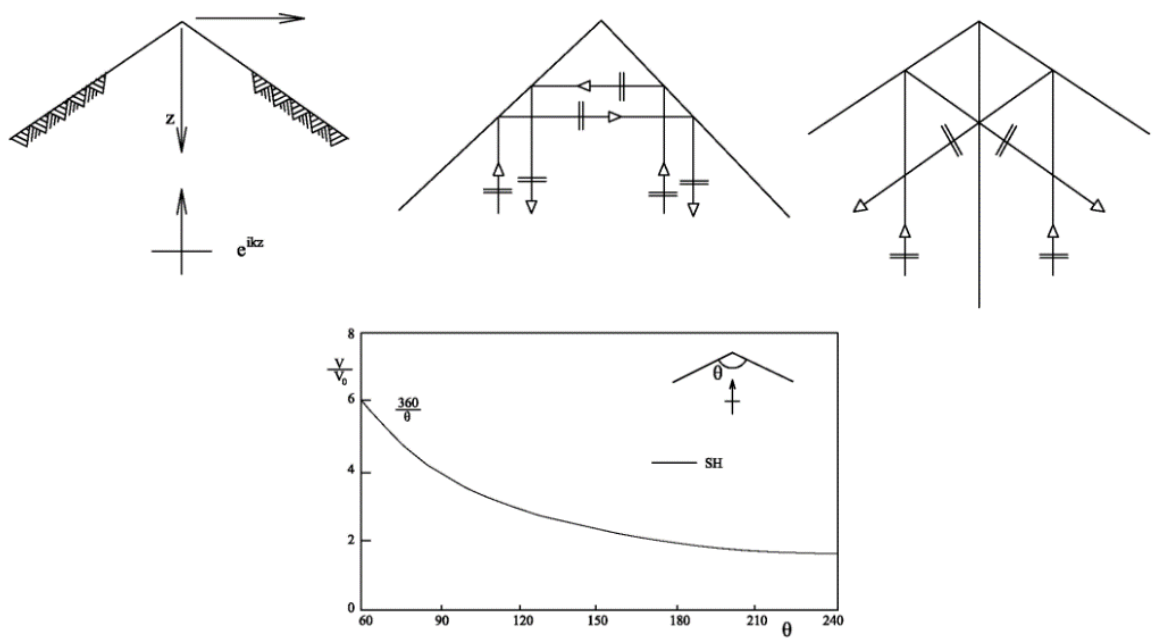

Fig. 3. Propagation of SH-waves running vertically from below in a media bounded by two intersecting flat surfaces in the shape of a wedge. If the wedge angle is $2 \pi / \mathrm{n}, \mathrm{n}$ different waves propagating at each point of the medium are formed: an incident wave, a reflected wave, and multiple $(\mathrm{n} \geq 4)$ reflected waves. All waves constructively interfere at the vertex, and the resulting oscillation amplitude is $n$ times greater than the amplitude of the incident wave. The waves corresponding to $n=3$ and $\mathrm{n}=4$ are shown; in the lower figure there is the resulting motion at the vertex as a function of the wedge angle [10].

The "topographical effects" observed in case of strong earthquakes are qualitatively consistent with the theory in terms of amplification of vibrations on hilltops and attenuation in lowlands. This gain is more pronounced on the horizontal components than on the vertical ones, and of the two horizontal components the vibrations in the direction perpendicular to the ridge axis are most amplified. The greater the average slope steepness, the higher the gain at the top. The oscillations amplification and attenuation to the maximum extent is observed at wavelengths comparable to the horizontal dimensions of large terrain irregularities [11]. The degree of amplification of seismic vibration parameters is very different and has significant variations even within a single slope.

One of the most striking manifestations of the terrain influence was recorded instrumentally on a steep slope in the Southern Alps, where the intensity of vibrations changed 10 times in the frequency band 5-10 Hz. Another example is the 1994 earthquake in Northridge (USA), when a five-fold increase in vibrations at frequencies of about $3 \mathrm{~Hz}$ registered by the Tarzan station $[12,13]$ was witnessed.

According to the data obtained in the course of the study on the physical model of seismicity influence (Sukhumi) [14], it can be determined that with the relief coefficients of 
the slope seismic accelerations increase by about 2.5 times in comparison to accelerations on horizontal sites. According to V. B. Zaalishvili's method, the effect of geomorphological conditions on the amplification is expressed by the following formula [15]:

$$
\Delta J_{3}=-0,71+0,53 \lg \cdot(\alpha \cdot H)+K
$$

where $\Delta \mathrm{J}_{3}$-increment of seismic intensity depending on geomorphological conditions, point; $\alpha \mathrm{H}$ - terrain relief coefficient: $\alpha$ - the angle of elevation, ${ }^{\circ}, \mathrm{H}-$ relative elevation, $\mathrm{m} ; \mathrm{K}-$ coefficient that determines the correction for the type of soil.

Intensity increment for the selected sample area in the apical zone:

$$
\Delta J_{3}=-0,71+0,53 \lg \cdot(27 \cdot 155)=1,21 \text { point. }
$$

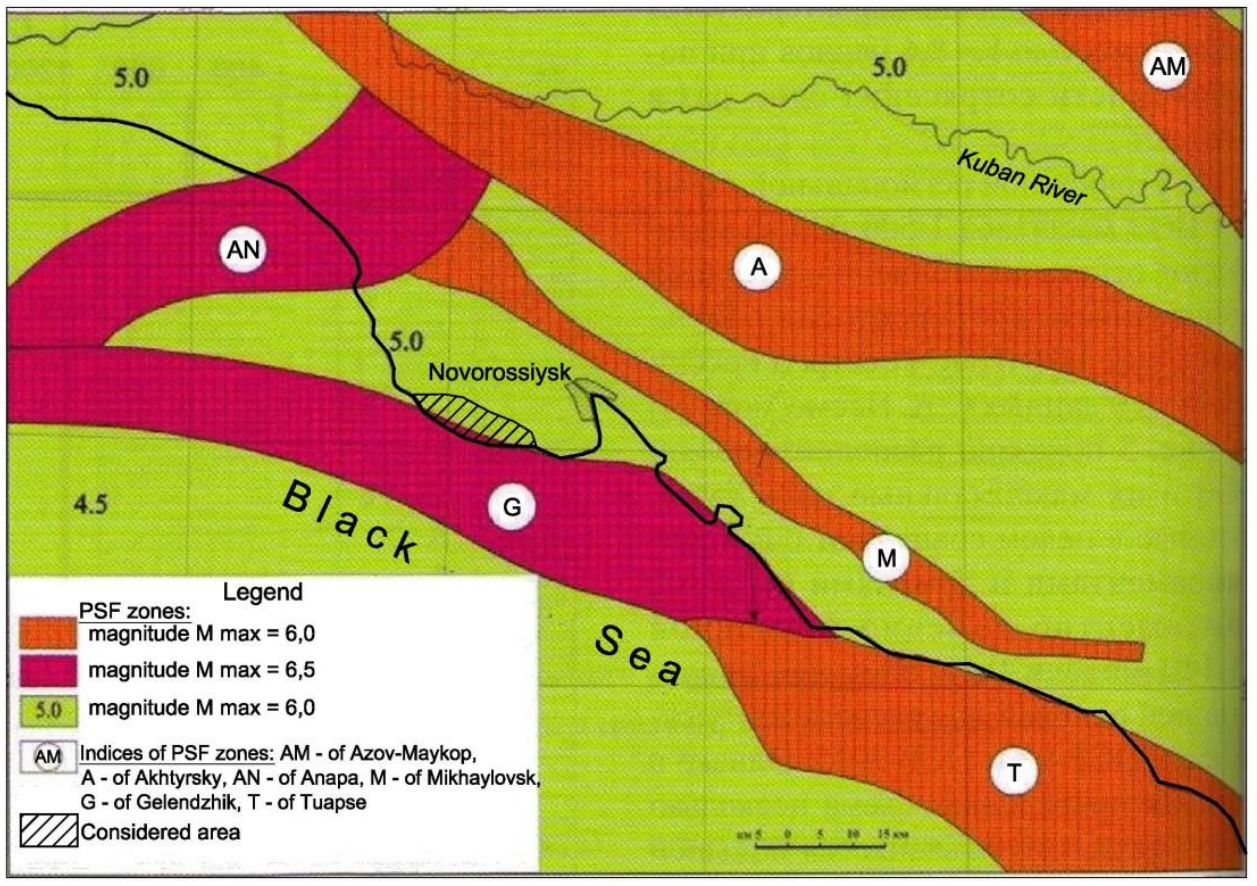

Fig. 4. Diagram of zones of possible earthquake foci [16].

The initial seismicity of this site for repeatability 1 time per 1000 years according to the map of General seismic zoning 2015 (B) is 8.6-8.7 points for "average" ground conditions [17]. Soils that were disturbed by previous stages of landslide, although they are mostly semihorizontal, should be classified as "average" in terms of seismic rigidity. Thus, calculated seismic impact for the upper part of this slope should be taken as 9.7-10.0 points, for the lower half of the slope - about 9 points.

Since the above-described effects of terrain influence have different effects on different parts of a potential landslide body, an attempt was made to take this into account in the stability estimations. To clarify the distribution in the massif of calculated peak seismic accelerations PGA, a calculation in the Matlab environment that implements THE Nera algorithm was used. 


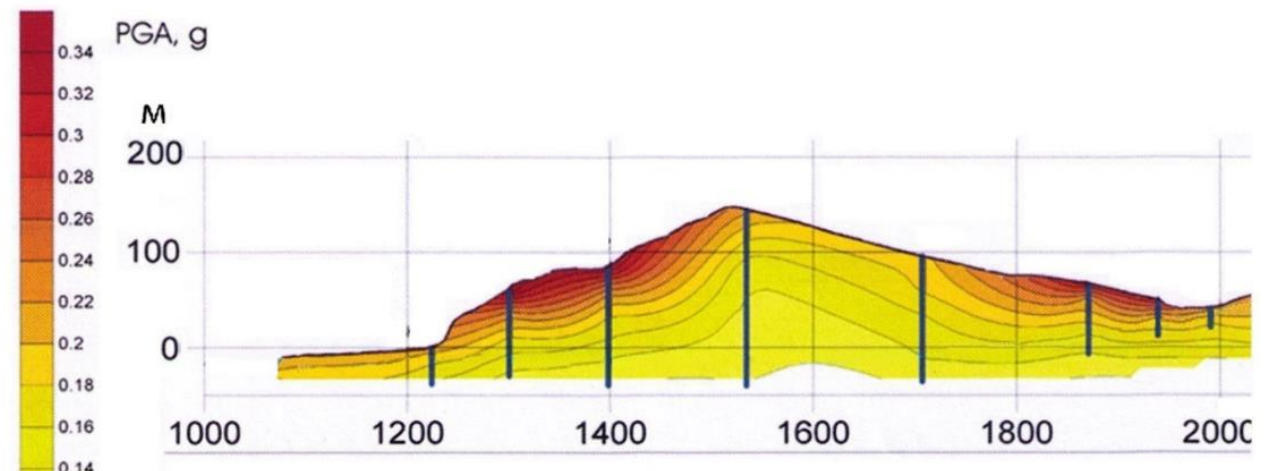

Fig. 5. The change in peak ground acceleration (PGA) is calculated in the Matlab environment that implements THE Nera algorithm.

The obtained values of calculated accelerations in the isolines were processed with the calculation of the weighted average PGA value within each calculated block (the horizontal step of the blocks is $10 \mathrm{~m}$ ) of the geomechanical model (Fig.6). The transition coefficient from the PGA value to the seismicity coefficient is assumed to be 0.5 in accordance with Eurocode 8 [18].

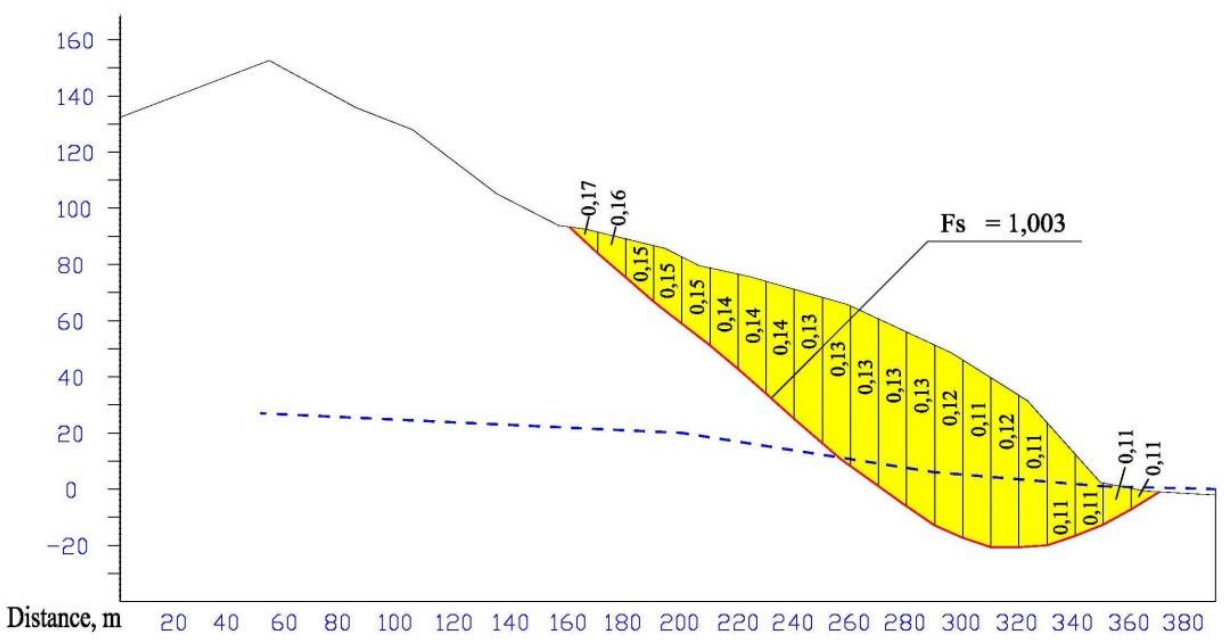

Fig. 6. Calculated values of KC seismicity coefficients for blocks of the geomechanical model.

Further refinement of the stability coefficient was performed on the basis of comparing the results obtained with a single seismicity coefficient for the slope massif as a whole and with separate accounting of the seismicity coefficient for blocks using the "leaning slope" principle according to the following formulas:

$$
\begin{aligned}
G_{i} & =P_{i} \cdot \sin \alpha_{i} \cdot \cos \alpha_{i} \\
& \frac{\sum_{i=1}^{n} G+\sum_{i=1}^{n} F_{H}^{d i v}}{\sum_{i=1}^{n} G+\sum_{i=1}^{n} F_{H}^{g e n}}=K_{1}
\end{aligned}
$$




$$
K_{s t}=\frac{K_{s t}^{g e n}}{K_{1}}
$$

where $P_{i}$ - weight of massif's block, $\alpha_{i}$ - inclination angle of the block displacement surface, $\mathrm{G}$ - horizontal component of the shear force in the block, $\mathrm{F}_{\mathrm{H}}{ }^{\mathrm{div}}$ - horizontal seismic force for a block with separate accounting of the seismicity coefficient for blocks, $\mathrm{F}_{\mathrm{H}}{ }^{\text {gen }}$ - horizontal seismic force for a block with a single seismicity coefficient for the slope massif as a whole, $\mathrm{K}_{\mathrm{st}}{ }^{\mathrm{gen}}$ - stability coefficient in case of single seismicity coefficient for the slope massif as a whole.

The computed ratio $\mathrm{K}_{1}=1,077$.

With a minimum stability coefficient of 1.08 obtained using a single Kc the true stability coefficient is: $K_{s t}=\frac{1,080}{1,077}=1,003$

Thus, the calculation of seismic acceleration fields using specialized programs in combination with stability estimations with differential accounting of seismic accelerations allows to specify the stability degree of arrays and parameters (volumes, dimensions in plan, depth of capture) of potential landslide events.

Of interest is also a joint consideration of seismic forces (acceleration, frequencies, duration) and their directions in three-dimensional space.

Waves generated in earthquake sources are emitted in all directions. When propagating through the soil layers, they are scattered, reflected and refracted in accordance with Snell's law of refraction:

$$
\begin{gathered}
\frac{\sin \theta_{1}}{V_{1}}=\frac{\sin \theta_{2}}{V_{2}} \\
\sin \theta_{2}=\frac{V_{2}}{V_{1}} \sin \theta_{1}
\end{gathered}
$$

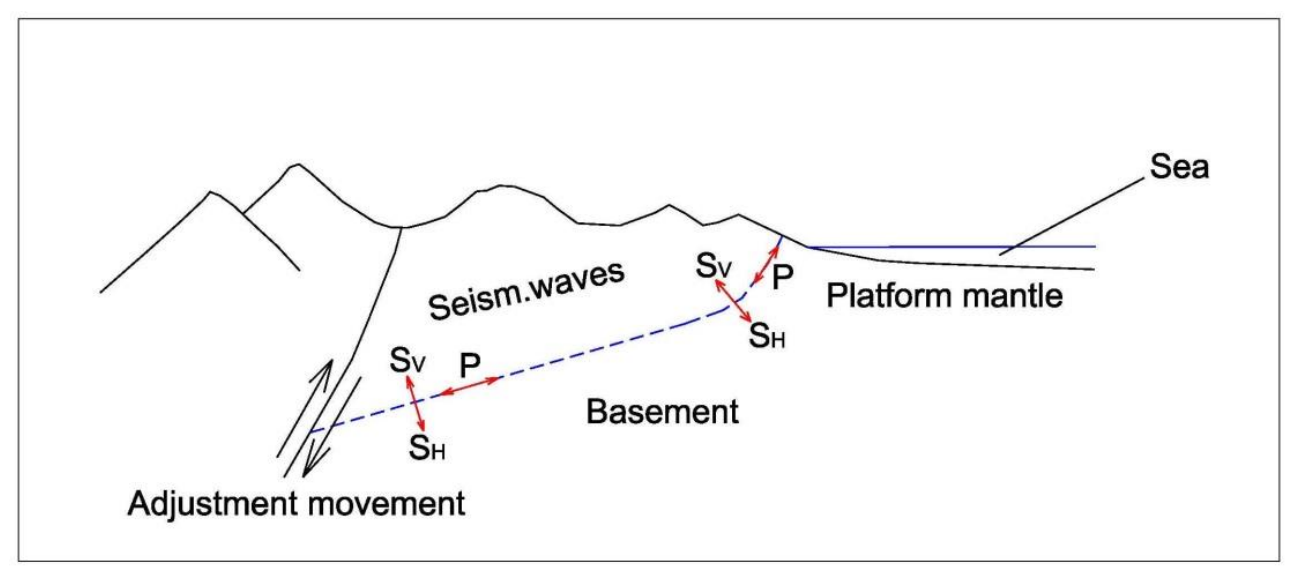

Fig. 7. Propagation of seismic waves from the seismal focus up to the surface. Waves: P longitudinal, SV - transverse vertically polarized, SH - transverse horizontally polarized. 


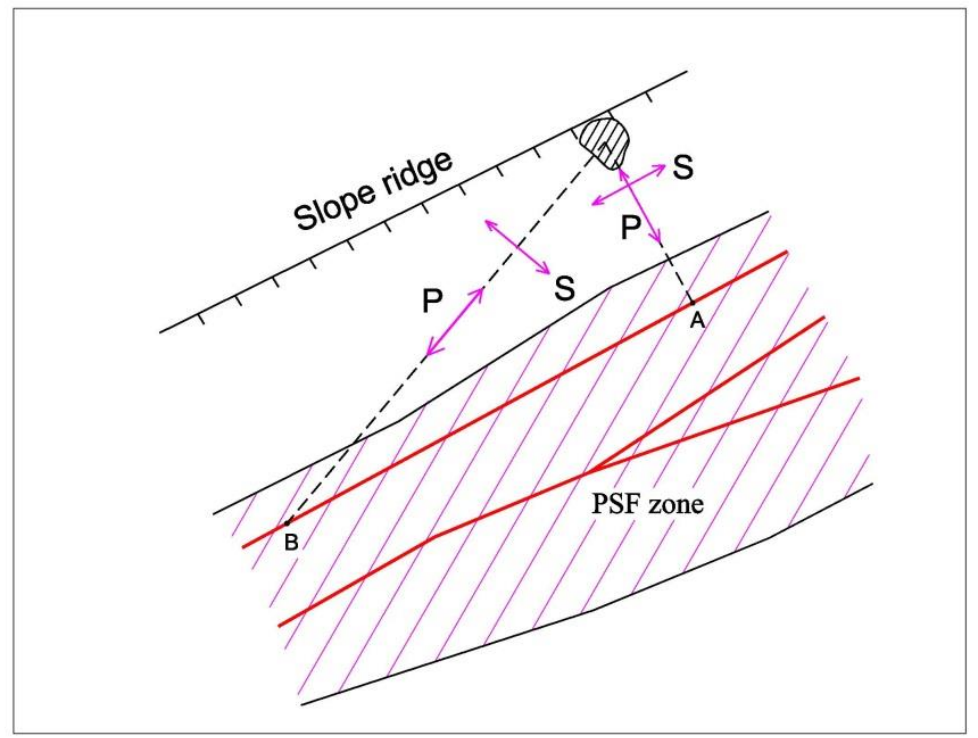

Fig. 8. Scheme of differences in the direction of seismic effects depending on the planned location of the earthquake source relative to the considered slope section. Red colour indicates seismic generating faults.

Since the seismic properties of the surface layers are usually lower than in the deep parts of the massif, the steepness of the trajectory of seismic waves at the earth surface increases due to refraction. With differences in seismic rigidity characteristic of the soils of the epicentral zones and slope massifs of the Western Caucasus, composed of rock and semirock formations, typical depths of the foci of the most dangerous PSF (possible seismic foci) zones are 10-15 km [17] and horizontal distances to the estimated slope massifs are 10-50 $\mathrm{km}$, in the near-surface the wave approach angle will be approximately in the range of 50-75 degrees from the horizontal.

When the earthquake center is located at the base of the slope for the selected sample area, the seismic effect of longitudinal waves, even in the "down" phase, has a significant "pressing" component, normal to the potential displacement zone (Fig.9). Transverse waves at a wavelength of 300-400 $\mathrm{m}$ will have a multidirectional effect on the stress state along the length of the landslide. For part of the array their impact will have a certain vertically upward component and a horizontal component directed down the slope, while in the other part of the massif seismic forces are directed deep into the slope (Fig.9), increasing the resistance. Thus, the most likely is the occurrence of a seismogenic landslide that covers only part of the slope - in this case, more likely the lower one, worked up by sea abrasion. 


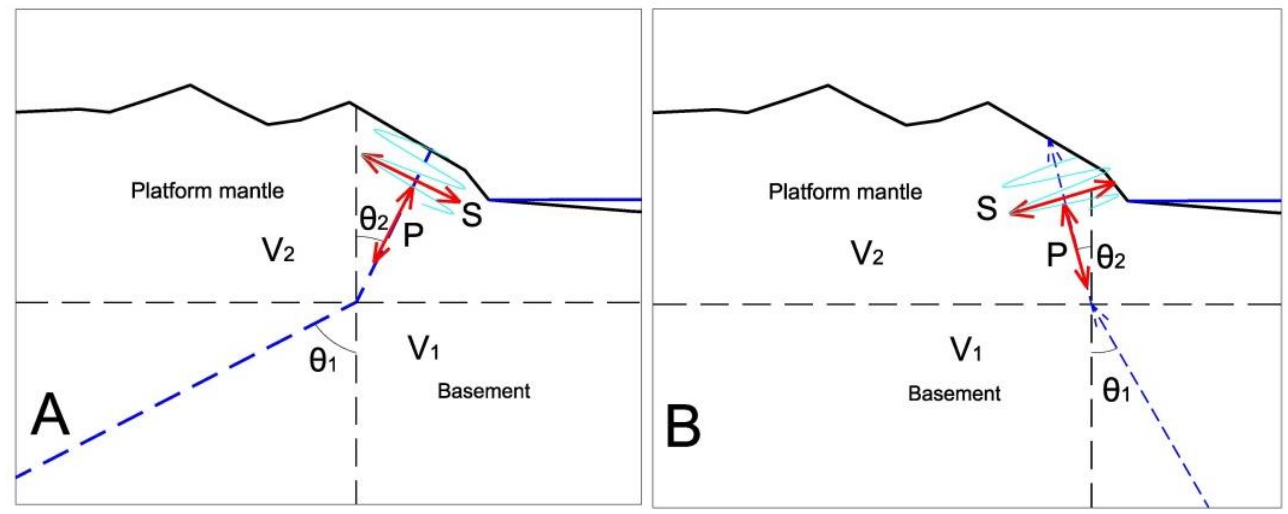

Fig. 9. The approach of the seismic wave to the area under consideration is from: A - the PSF zone of Gelendzhik (maximum magnitude - 6,5 at an average depth of $15 \mathrm{~km}$ [17] and an epicenter distance of 8-9 km, $V_{1} / V_{2}=2, \Theta_{1}=30^{\circ}$, from where $\Theta_{2}=14,5^{\circ}$ ), $\mathrm{B}$ - the PSF zone of Mikhailovsk (maximum magnitude -6 at an average depth of $10 \mathrm{~km}$ and an epicenter distance of about $20 \mathrm{~km}, \mathrm{~V}_{1} / \mathrm{V}_{2}=2$, $\Theta_{1}=63^{\circ}$, from where $\left.\Theta_{2}=26,5^{\circ}\right)$.

More dangerous is the arrival of a seismic wave from the opposite side, "from behind" the slope, when the wave will come to the surface of the slope almost normal. In this region this corresponds to the occurrence of an earthquake in the PSF zone of Mikhailovsk (Fig.4), located further from the considered coastal area and characterized by smaller possible magnitudes.

If the seismic center is located not opposite the landslide slope, the angles of waves approach will, of course, be much higher, but the refraction of the waves leads to the fact that the angles of their approach near the earth's surface $\theta_{2}$ will only increase by $5-15^{\circ}$.

The impact of transverse seismic waves, of course, also decreases with increasing distance from the landslide site to the seismic center, but otherwise it changes in a different way. The azimuth change does not affect action of the vertically polarized waves at all, while the impact of horizontally polarized transverse waves becomes even more unfavorable for the stability of the slopes as the seismic center moves away from the landslide-prone slope (Fig.8).

\section{References}

1. S.G. Mironyuk, V.Y. Ionov, Geological processes as hazards to the buildings: Materials of International symposium dedicated to PhD in geological and mineralogical sciences V. P. Homenko 70 ${ }^{\text {th }}$ birth, 33-39 (MGSU, Moscow, 2019) DOI: 10.22227/978-5-72641933-6.2019.33-39

2. E.A. Rogozhin, A.N. Ovsyuchenko, A.I. Lutikov, A.L. Sobisevich, L.E. Sobisevich, A.V. Gorbatikov, Endogenous hazards of Greater Caucasus (IPE RAS, Moscow, 2014)

3. M.P. Kropotkin, Engineering survey 1, 20-30 https://www.engineeringsurvey.ru/jour/article/view/384?locale=ru_RU

4. E. Hoek, Putting numbers to Geology - an Engineering viewpoint. Felsbau 3 (1999)

5. H. Pedersen, B. Le Brun, D. Hatzfeld, M. Campillo, P.-Y. Bard, Bull. Seism. Soc. Am. 84, 1786-1800 (1994)

6. P.-Y. Bard, 10 th ECEE Proceedings, 305-324 (Balkema, Rotterdam, 1995)

7. S.J. Nava, J.W. Munsey, A.C. Johnson, Seis. Res.Letters 60, 119-129 (1989) 
8. Y. Umeda, Int. Symp. Earthq. Source Physics and Earthquake Precursors Proceedings, 19-22 (Tokyo, 1990)

9. F.J. Sanchez-Sesma, J.L. Rodrigues-Zuniga, L.E. Perez, Bull. Seism. Soc. Am. 85, 890899 (1995)

10. F.J. Sanchez-Sesma, Bull. Seism. Soc. Am. 80, 737-742 (1990)

11. L. Geli, P.-Y. Bard, B. Jullien, Bull. Seism. Soc. Am. 78, 42-63 (1988)

12. M. Celebi, Third Int. Conf. on Recent Advances in Geotechn. Earth. Engineering and Soil Dynamics 3, 1411-1416 (ST.Louis, 1995)

13. M. Bouchon, J.S. Barker, Bull. Seism. Soc. Am. 80(1a), 66-72 (1990)

14. V.B. Zaalishvili, Seismic microzoning of urban and construction site territories (Nauka, Moscow, 2009)

15. A.D. Nazimova, A.V. Gavrilov, E.V. Kalinin, A.V. Bershov, Engineering geology 5, 32-38 (2016) https://elibrary.ru/item.asp?id=27224150

16. S.A. Nesmeyanov, Geoecology, engineering geology, hydrogeology, geocriology 1, 528 (2012) http://www.geoenv.ru/index.php/ru/zhurnal-qgeoekologiyaq/252-2012/566zhurnal-geoekologiya-1-2012\#abstract_1

17. B.A. Trifonov, V.V. Sevost'yanov, Engineering survey XII(5-6), 82-90 (2018) https://www.engineeringsurvey.ru/jour/article/view/512

18. European standard NF EN 1998-5, Eurocode 8 (Comite Europeen de Normalisation (CEN), Brussels, 2014) 